Published in final edited form as:

Transcult Psychiatry. 2020 February ; 57(1): 124-139. doi:10.1177/1363461519858446.

\title{
Mechanisms and perceived mental health changes after a livelihood intervention for HIV-positive Kenyans: Longitudinal, qualitative findings
}

\author{
A.M Hatcher ${ }^{\star}$, \\ University of the Witwatersrand and an Honorary Researcher at the University of California, San \\ Francisco \\ L. Lemus Hofstedler, \\ UC Berkeley-UCSF Joint Medical Program \\ K. Doria, \\ Yale University \\ S. Dworkin, \\ University of Washington Bothell School of Nursing and Health Studies \\ E. Weke, \\ Kenya Medical Research Institute (KEMRI)
A. Conroy,
Center for AIDS Prevention Studies at the University of California San Francisco
E. Bukusi,
Kenya Medical Research Institute (KEMRI), University of Washington and University of California San Francisco.

\section{C.R Cohen,} \\ Department of Obstetrics, Gynecology \& Reproductive Sciences at the University of California \\ San Francisco (UCSF) and University of California Global Health Institute (UCGHI)

\section{S.D. Weiser} \\ Division of HIV, Infectious Disease and Global Medicine at UCSF
}

\section{Abstract}

\begin{abstract}
Background-While food insecurity and poverty worsen mental health outcomes among people living with HIV/AIDS (PLHIV), few interventions studies have targeted poverty and food insecurity as a way to improve mental health. Among HIV-positive patients, addressing such upstream determinants may prove crucial to ensure better mental health and HIV clinical outcomes.
\end{abstract}

Methods-We integrated longitudinal, qualitative research into a randomized trial of a livelihood intervention to understand processes and mechanisms for how the intervention may affect mental

*Corresponding author: Abigail M Hatcher, Division of HIV/AIDS, Department of Medicine, University of California, San Francisco, 995 Potrero Avenue, San Francisco General Hospital, San Francisco, CA 94110, hatchera@ globalhealth.ucsf.edu. 
health among HIV-infected Kenyan adults. In-depth interviews were conducted with intervention participants $(n=45)$ and control participants $(n=9)$ at two time-points (after intervention start and upon intervention end). Interviews ( $n=85$ ) were translated and double-coded, and analyzed thematically using an inductive-deductive team approach.

Results-Participants reported numerous mental health improvements post-intervention including reduced stress, fewer symptoms of anxiety, improved mood, fewer depressive symptoms, fewer repetitive and ruminating thoughts, and more hopefulness for the future. Improvements in mental health appear to occur via several mechanisms including: 1) better food security and income; 2) increased physical activity and ability to create fruitful routines around farm work; and, 3) improved sense of self as an active member of the community.

Limitations-Qualitative, longitudinal interviews may help identify intervention mechanisms for improved mental health, but additional research is required to confirm self-reports of mental health changes.

Conclusions-These findings suggest that livelihood interventions may improve mental health in multi-faceted ways, and help PLHIV better integrate with their communities.

Trial registered at ClinicalTrials.gov—-[number redacted for blinding]

\section{Keywords}

mental health interventions; food insecurity; livelihoods; Kenya; qualitative research

\section{Introduction}

Common mental health disorders, such as anxiety and depression, are important contributors to disability-adjusted life years in resource-constrained countries (Steel et al., 2014). People living with HIV/AIDS (PLHIV), in particular, have a high burden of mental illness, which can worsen both physical and mental health outcomes (Chibanda, Benjamin, Weiss, \& Abas, 2014). In sub-Saharan Africa (SSA), pooled analysis suggests that one in three HIV-positive patients exhibit depressive symptomology, and 13-18\% report major depression (NakimuliMpungu et al., 2012; Tsai, 2014). Depression among PLHIV, in turn, is associated with higher viral loads (Evans et al., 2002), faster disease progression and mortality (Antelman et al., 2007).

It is well-documented that food insecurity, socio-economic status and financial stress are related to common mental disorders (Lund et al., 2010). In the general population, poverty and food insecurity are associated with worse mental health functioning (Subbaraman et al., 2014). Among HIV-positive patients, longitudinal and cross-sectional studies have highlighted an association between food insecurity and depression in SSA (Hadley \& Patil, 2006; Hadley et al., 2008; Tesfaye et al., 2016; Tsai et al., 2012b). Household food insecurity is also associated with lower mental health-related quality of life scores among HIV-positive patients in SSA (Palermo, Rawat, Weiser, \& Kadiyala, 2013; Tesfaye et al., 2016; Weiser et al., 2012).

Practitioners and scholars increasingly recognize that mental health is unlikely to adequately improve unless structural barriers, such as food insecurity, poverty, and social exclusion are 
addressed (Burgess, 2015; Kidia et al., 2015; Nakimuli-Mpungu et al., 2014). Theoretically, this aligns with the "social causation" hypothesis, which suggests that poverty underscores mental health outcomes due to the strong links between economic resources and stress, social exclusion, and exposure to other social dynamics such as violence (Flisher et al., 2007; Patel \& Kleinman, 2003). A renewed emphasis on poverty being intertwined with mental health is also an extension of the biospychosocial model, which positions mental health within social drivers such as socio-economic status (Hatala, 2012). Given this relationship between poverty and mental health, livelihood programs that aim to improve food insecurity may improve mental health symptoms concurrently. However, in a recent review of mental health interventions for PLHIV, none were focused on structural drivers of mental health (Sikkema et al., 2015). Interventions that focus specifically on nutrition, without structurally addressing livelihoods or food security, have found mixed results. A food basket program in Uganda improved household food security and physical quality of life compared to a matched comparison group receiving otherwise similar HIV care (Rawat, Faust, Maluccio, \& Kadiyala, 2014), but made no measureable difference on mental health (Maluccio, Wu, Rokon, Rawat, \& Kadiyala, 2016). In South Africa, no differences were noted in general quality of life (a measure comprised of both physical and mental health) between recipients and non-recipients of nutrition support services (Oketch, Paterson, Maunder, \& Rollins, 2011).

There have, on the other hand, been an increasing number of studies on economic interventions and their impact on the mental health of non-HIV-infected populations. A systematic review found mixed evidence for the effect of poverty alleviation programs on mental health outcomes (Lund et al., 2011). Since publication of the systematic reviews, several additional trials have been completed. In Kenya and Mexico, cash transfers reduced depressive symptoms among participants (Kilburn, Thirumurthy, Halpern, Pettifor, \& Handa, 2016; Ozer, Fernald, Weber, Flynn, \& VanderWeele, 2011). These quantitative findings align with qualitative research suggesting cash transfers can reduce stress, anxiety and depression in varied populations (Owusu-Addo, Renzaho, \& Smith, 2018). However, in Nicaragua and Zambia, women participating in cash transfers had no difference in depressive symptoms or perceived stress (Macours, Schady, \& Vakis, 2012).

Microfinance interventions have similarly had mixed impacts on mental health. While several studies suggest that microfinance improves mental health (Becchetti \& Conzo, 2010; Mohindra, Haddad, \& Narayana, 2008; Pronyk et al., 2008), others show no significant impact or mixed results (Ahmed, 2005; Christy-McMullin, Shobe, \& Wills, 2009; Han, Grinstein-Weiss, \& Sherraden, 2009; Karlan \& Zinman, 2010; Kayser, Lombe, Newransky, Tower, \& Raj, 2010; Masud Ahmed \& Chowdhury Abbas, 2001). In addition, one RCT suggests declines in mental health following access to microfinance (Fernald, Hamad, Karlan, Ozer, \& Zinman, 2008). Some analyses suggest a relationship between microfinance and increased rates of suicide, particularly among men (Ashta, Khan, \& Otto, 2015). This literature highlighting the immense stress of loan repayment have led some practitioners to develop refined forms of microfinance, including flexible loan repayment (Field, Pande, Papp, \& Park, 2012) and a new emphasis on savings over credit (Ssewamala, Neilands, Waldfogel, \& Ismayilova, 2012). 
Distinct from cash transfers and microfinance are livelihood interventions, which focus on building skills or capital over time. Few studies to date have rigorously tested through randomized control trials the impact of livelihood interventions on mental health. In one study, women receiving livestock assets in Democratic Republic of Congo had decreased depressive symptoms over time (Glass, Perrin, Kohli, \& Remy, 2014). However, it is less clear how and why such livelihood interventions may lead to mental health changes, and specifically from the perspective of local communities and stakeholders in which such interventions are embedded (Jain \& Orr, 2016). We examined how a multi-sectoral livelihood intervention affected mental health for HIV-positive farmers in Kenya. Using qualitative methodology, we explored participant definitions of mental health, perceived changes in mental health due to the intervention, and mechanisms through which the intervention may have influenced mental health outcomes.

\section{Methods}

\section{Setting}

The study was conducted in Migori County in the former Nyanza region of Kenya where the vast majority of individuals are food insecure (Kenya National Bureau of Statistics, 2008). This region has the highest HIV prevalence in Kenya, at 15.1\% (Kenya National Bureau of Statistics and ICF Macro, 2010), and is a region that has a high burden of depression (Ngui, Khasakhala, Ndetei, \& Roberts, 2010). Details of the Shamba Maisha (meaning "farming life" in Kiswahili) study design have been previously described (Cohen et al., 2015). In brief, we conducted a pilot randomized controlled trial in two communities to explore whether Shamba Maisha improved food security and HIV clinical outcomes among farmers.

The two sites selected for this study were chosen based on similarities in clinic size and agricultural characteristics (access to water, size of homesteads). The two sites were randomly assigned to either intervention or control conditions by a biostatistician who was not involved in fieldwork. Participants were recruited through organized meetings held at each health facility and announcements at patient support group sessions. Individuals who expressed interest were screened for eligibility and consented. Inclusion criteria for the trial and hence the current qualitative study included: HIV-infected and receiving ART, ages 18to 49-years old, having access to farmland and surface water, being moderately or severely food insecure at baseline or malnourished during the year preceding enrollment, and participating in or being willing to join a patient support group. Participants were enrolled starting in August 2012 and followed for one year.

A cross-disciplinary team of experts on agriculture, development and HIV-related health designed the intervention, intended to sustainably improve food insecurity and HIV clinical outcomes (including mental health). The Shamba Maisha intervention was comprised of three components, delivered as a package to intervention participants (Cohen et al., 2015): 1) "MoneyMaker" Hip Pump, a low-cost micro-irrigation water pump, which enabled farmers to irrigate their crops year-round, avoiding dependence on seasonal rainfall thus capitalizing on higher crop prices in the marketplace; 2 ) training on sustainable farming practices and financial management delivered to groups of participants in eight didactic and practical demonstration sessions; and 3) loan program of vouchers (worth $\sim \$ 150$ USD) to purchase 
the irrigation hip pump, seeds, fertilizers, and other farming implements. Study participants were expected to repay the loan in full by the end of two harvest seasons, but were not required to forfeit personal belongings (other than the hip pump) if they failed to repay the loan. Trainings and loan repayment occurred in the context of patient support groups.

\section{Data collection}

We integrated a longitudinal qualitative study into the pilot trial, aiming to unpack the mechanisms behind intervention impacts (Zakaras et al., 2016). The purpose of the current manuscript is to explore the mental health impacts of the intervention. We developed a 'theory of change' to explain how livelihoods intervention may work towards improvements in multiple aspects of participant lives, and that improvements in mental health may be on the causal pathway towards improved HIV outcomes (Figure 1). Our goal was to use longitudinal qualitative data to assist with refining the theory of change.

Overall, 85 in-depth interviews were conducted. We interviewed a purposive sample of intervention participants $(n=45)$ and a subset of control participants $(n=9)$ with the aim to recruit a wide range of ages, and both male and female participants. Our purpose in interviewing control participants was to ascertain whether the impacts and mechanisms described by intervention participants were related to the intervention or to study participation more broadly. All participants approached for the qualitative sub-study agreed to participate.

A subset of 31 intervention participants were followed longitudinally, with one interview early in the intervention (at 3 to 5 months after enrollment) and a second at intervention end (12 months after the start of the intervention). The longitudinal approach to data collection allowed a better understanding of intervention effects over time. Control participants were interviewed at the intervention end only, or 12 months after enrollment.

Interviews were conducted by four local researchers (two male, and two female) who were fluent in local languages (Dholuo and Kiswahili) and English. Researchers held either bachelor or masters degrees and were trained extensively on qualitative research techniques. This training included interviewing in an exploratory, non-judgmental, non-leading way and probing for rich descriptions of participants' experiences (Bernard, 2006; Patton, 2002). We carried out mock and pilot interviews to standardize techniques within and across interviewers. In addition to undergoing extensive training, study investigators (AMH, SLD, SDW) reviewed early transcripts to provide feedback on interview and probing style.

Each interview took place in a private location of the participants' choosing such as their home or the study office. Interviewers were gender-matched with participants. Interviews lasted between 45 minutes and 2.5 hours and were digitally recorded. Only the researcher and respondent were present during the interviews, and none of the interviewers were previously known to study participants to encourage an unbiased accounting of positive and negative experiences with the intervention. Researchers were hired specifically for qualitative research and were managed separately from the team delivering the Shamba Maisha intervention. 
The interview guides at baseline aimed to elicit feedback about particular topics in the daily lives of participants, such as household composition, food, healthcare, partner dynamics, and farming decisions. To explore mental health, participants were asked about whether they had felt down, anxious, or sad and what causes sadness or stress in their lives. Follow-up interviews with the same participants addressed the same set of questions at a new timepoint 7-9 months later. Interviewers at follow-up asked about any changes (positive or negative) related to mood, stress, anxiety, or sad emotions, with specific emphasis on asking participants to describe their own views on mental health. Participants were asked whether feelings of stress, sadness or anxiety had changed at all in the previous year. They were also asked to describe the reasons underlying any changes in these feelings.

\section{Data analysis}

Interviewers transcribed and translated their own interviews into English. Each transcript was reviewed by a co-investigator to ensure clarity of the translation. This step also served as a training technique, since the co-investigator could identify areas where further probing might be warranted. Individual transcripts were labeled based on the location, age, and gender of the participant. Each transcript was given a pseudonym to ensure anonymity and to link participants from the two interview timepoints.

Data were managed using Dedoose (SocioCultural Research Consultants, 2013), a qualitative software that allows for real-time access to a secured database by a number of people in an analysis team. Several co-authors developed a thematic coding framework based on the topics covered in interview guides. The framework was shared with other coinvestigators and data collectors and revised through a series of teleconferences. Once the framework was established, all codes and their definitions were imported into Dedoose to aid a first round of coding. This first round of coding focused on highlighting large chunks of data and placing them within one or more relevant "broad codes".

For this analysis, fine codes were developed using a team-based, constructivist approach to qualitative analysis. Three authors printed out excerpts from the Dedoose dataset related to mental health and individually hand-coded sub-themes related to mental health. While fine codes were certainly informed by 'sensitizing concepts' (Charmaz, 2008), there was an effort to apply codes based on inductive techniques; we prioritized views and voices of participants over pre-identified constructs. The three researchers then met to build consensus and clarify a full list of fine codes (Table 1).

Next, the same three researchers wrote analytical reports to describe each fine code alongside illustrative quotes. We selected quotes that were representative of the cohort, with special attention paid to divergent quotes (those in which participants' experiences differ from other participants). Lastly, the analytical reports were re-organized with an aim of generating theoretical constructs that extend the knowledge of the field (Tweed \& Charmaz, 2012). All quotes presented here include participant demographics, and where possible, a longitudinal perspective is explored. 


\section{Ethical considerations}

Informed, written consent was obtained by all participants. Transportation reimbursement was offered up to 800 Kenya shillings per clinic-based interviews ( $\$ 9.4$ USD) and 400 Kenya shillings for home-based interviews ( \$4.70). Ethics approval was obtained from Kenya Medical Research Institute (SSC \# 2178) and the University of California San Francisco (CHR \#11-07435). This trial is registered at ClinicalTrials.gov (NCT01548599).

\section{Results}

\section{Participant characteristics}

The participant cohort included 54 HIV-infected participants, of whom 45 were in the intervention arm and 9 in the control arm (Table 2). The cohort was comprised of a similar proportion of women and men, with an age range between 23 to 56 years. A majority of participants (86\%) had been on ART for at least two years prior to enrolling in the study. Many had long-term experience as farmers prior to participating in the Shamba Maisha trial.

\section{Perceived mental health improvements}

Participants described multiple aspects of mental health that improved through participation in Shamba Maisha (see Table 3), including changes in stress, anxiety, and depression, and also attributed changes in their HIV-related health in part to these mental health changes.

Participants often reflected that they experienced less stress after taking part in the intervention. Several participants described that the intervention helped raise CD4 counts by decreasing stress levels. A 32-year-old man described his CD4 improving from 640 at the start of the intervention to 1000 , a shift that was accompanied by a decrease in viral load. He noted that as he put his "entire mind on work and didn't have any other thoughts," he was able to "focus all the energy (keto teko duto)" on other matters such as taking medication on time, eating well, and staying healthy.

Multiple participants illustrated their reduction in anxiety by describing how their mind is "settled" or "clear," an important way of articulating good mental health in this setting. One 33-year-old man explained that less anxiety around hunger helped him "have a very clear mind (bedo kod paro ma liw) [because] I am not worried of sleeping on an empty stomach." Many participants described fewer symptoms of depression after taking part in the intervention. These shifts in mental health are explored further in the following sections, which explain specific mechanisms around improved mental health.

\section{Mechanisms towards improved mental health}

Participants in our study perceived that mental health was altered through several key mechanisms, including: improved food security and ability to provide for family, more productive daily routines (thereby reducing time for and attention to persistent fears), enhanced social standing that accompanied being more active community members. Concerns over repaying loans, however, were a significant perceived negative mental health outcome of the intervention. 


\section{Improved food security reduces anxiety and depressive symptoms-}

Participants described that their feelings of depression and hopelessness related to difficulties accessing food and providing for their families. Hunger itself was described as a trigger for anxiety, stress, and depression by one 30-year-old woman, who explained that "when one is full they are more rational but when one is hungry they get anxious and stressed, leading to depression." She further articulated that, "when I do not have food, I think a lot about what I would cook at a certain meal and wonder what to do."

Participants noted that the intervention decreased stress in the household by improving food availability. A 28-year-old mother explained that she "used to be stressed about how the children were going to eat." Yet, when the anxiety of finding food was alleviated, she was able to "eat and laugh happily" with her family. Similarly, a 33-year-old man who reported experiencing "having no food" during the early interviews discussed how participation in Shamba Maisha improved his food situation and reduced anxiety: "I am not worried, knowing that we will eat vegetables, so it covers the part where I could have been forced to go look for food." These examples underscore important gendered aspects of food provision, with women being predominately concerned with putting food on the table, whereas men spoke more about finding work to pay for food.

Several participants described how improved food insecurity positively affected their mental health. One widowed woman who had been inherited by an extended family member explained the reduced worry and sense of calm that arose out of having sufficient food for her three children:

\section{I am calmer and happier as I am able to provide enough food for my family. I do not have to worry about what my children will eat at all. Before Shamba Maisha I had to strain to be able to buy omena [small fish] or sugar but Shamba Maisha has now brought a lot of ease because the vegetable can be sold to get money to buy these things. When my partner comes home and finds me happy, he is also happy and everything goes well. (Female participant, intervention end, 38 years old)}

She also described that her relationship with her new husband improved as her own anxiety over caring for her family declined.

In the control site, several participants linked hunger to feeling "low". In one interview, a man spoke about hunger and "wishing for death" to avoid the suffering of living in poverty and in ill-health:

We even sleep hungry, and when we do not have money we could easily go to bed on empty stomachs. That coupled with my health makes me feel low (miyo abedo kod) and at times makes me wish for death because one doesn't see the need of suffering like that. (Male participant, control site, 40 years old)

For a woman in the control community, the stress of lacking food and money was sustained throughout her participation in the trial:

Interviewer (I): Tell me how you feel mentally each day. 
Researcher (R): There are some times that I feel lonely during the day but I have since learned to be reading my bible or listening to the radio so that I keep that feeling away.

I: What brings that feeling?

R: Lack of money to buy food or for accomplishing other plans brings this kind of feeling.

I: Share with me about a time when you were stressed.

R: Between November and January, I was stressed because I needed school fees for my children and I also had a patient whom I was taking care of. So yes I have had such an experience and when I went for the routine checkup my CD4 and weight was found to have reduced significantly.

I: How is the situation now?

R: I still experience a little stress.

I: What brought the stress?

R: A lack of food brings that. (Female participant, control community, 46 years)

Another mechanism linked to improved mental health was a decreased need to borrow food from one's neighbors and relatives. One male explained how borrowing money from family and neighbors would result in extreme shame, making him feel "useless" and giving him "worries." However, he noted that participation in Shamba Maisha provided him relief from financial stress:

But when the Shamba Maisha came, money for these petty things became available, and these small things may be petty, yes, but they really bring about psychological torture (to gikelo chandruok mar paro) which Shamba Maisha has gotten rid of. (Male participant, intervention end, 44 years old)

\section{Productive farming routines reduced depressive and worrisome thoughts-}

Many participants explained that staying engaged and busy through farming and participation in Shamba Maisha helped reduce stress. A 40-year-old woman described how "something funny about stress is that if you are just seated idle is when it increases, but when you are busy doing something your thoughts are reduced and the stress also goes down." She went on to say that when feelings of stress overwhelm her, she visits the farm as a way to stay busy and distract herself. Several other participants explained that becoming engaged in farming through Shamba Maisha helped to reduce existential worry about illness and death:

After realizing that I had the virus, I worried a lot about what the state of my children would be when I am dead, but with the [Shamba Maisha] teachings, that worry has now reduced. When I first learned of my status, I could think a lot about how I got infected by the disease. I even got worried about the life of my children after my death, which I saw was very near. But I have since changed and when I am going about my duties, I do them without the feeling that I will leave them 
behind... I just do them well and I feel a lot more free (thuolo mang'eny, literally

"opportunity of time"). (Male participant, intervention end, 43 years)

Farming also seemed to be an antidote for feelings of depression and isolation. One 32-yearold woman, whose child had recently passed away, explained that even though she could be spending her day sleeping, she would rather go to the farm for a bit of work. Similarly, the act of physically returning to the farm every day helped one 42 -year-old man create a regular routine, which reduced worrisome thoughts and helped him sleep "like a baby because most of the worries have been taken care of by Shamba Maisha."

Multiple participants described increased motivation and enthusiasm in general as they started to be more productive in the farm. One woman said that Shamba Maisha helped her stay organized and productive:

I: I have seen a big change as I am more enthusiastic (kendo, literally 'hope and optimism') and I feel recharged to farm much better than I used to. Now I concentrate a lot more on my farming.

I: What is the source of your enthusiasm to work?

$\mathrm{R}$ : What has brought about this enthusiasm is the way we were trained to farm, yeah.

...Sometimes I go to my farm and sing as I work, this helps me reduce the worries and have a good life.

I: Tell me more about Shamba Maisha reducing your worries.

R: Initially I used to be very idle; I had a lot of time and I would easily get stressed as I thought aimlessly. Shamba Maisha has made me very busy and organized. I have to plan how to do my work to fit in the available time, which has helped me progress, and I really like the life that I am now leading. (Female participant, intervention end, 48 years old)

The additional time on the farm seemed to clear this participant's thoughts, helping her concentrate and reducing worrying thoughts. Another participant described his productivity and motivation as a feeling of "alertness," helping him refrain from destructive thoughts by thinking creatively about the goals of his agriculture work:

SM has made me very alert. Now I have a plan to cultivate 1000 heads of watermelon. I have onions ready for transplanting in 1 acre, kales in the seedbed, which has got me thinking about its transplantation. My mind is therefore very packed (Pacha koro opong) all the time. For me to come here, I was called from the farm. Before I have destructive thoughts; now I think about my crops in the garden. (Male participant, early intervention, 33 years old)

For one man in the control community, worrying thoughts took hold at night, when he ruminated about dying and wondered how long the HIV medication might help him live:

The only thing that stresses me a lot is dying. I normally feel that I am an already dead person who is just taking the ARVs to extend my life up to a given time and 
then I just die. I am mostly disturbed when I am going to bed. (Male participant, control site, 40 years old)

Reframed social identities: Future outlook and self-esteem-Taking part in Shamba Maisha helped participants to be more hopeful about their future. One man explained that his depressive thoughts lifted and he regained hope since participating in Shamba Maisha due to his new ability to work:

After going for the [HIV] test and discovering that I was sick, I saw no future. I thought that I was done with this life. There is a question they asked here, that "Have you have ever felt in your heart for 3 months that you have no life?" and that is something that has happened to me. But when I sat down alone later, I felt that my heart should not lose hope, because I am someone who is working, God has given me life.... and we also have Shamba Maisha and they tell us that they have come to uplift our living standards. When you have that hope then there is some little help that you also get. (Male participant, early intervention, 35 years old)

The identity of being "someone who is working" was a shift in social identity for this young man. Other participants reported improved mood and less anxiety as they came to view themselves as more productive, and had less anxiety about household food supplies. One 40year-old man stated that prior to Shamba Maisha he felt "hopeless and scared," but that the project gave him "the will to go about duties and [the] farm from which I get food and money."

These new livelihood opportunities led to improved feelings of self-efficacy, which were paralleled by positive changes in one's sense of self within the broader community. Intervention participants were viewed by their community as increasingly important, active members of society who were worthy of visiting and conducting business with. The change in participants' economic standing was accompanied by a change in social standing. Several participants echoed a similar theme throughout their narratives about the diminishing distance between them and the community. In this way, individual changes in mental health and self-efficacy were embedded within the social and communal aspects of mental health (e.g. respect, connectedness) that were crucial for research participants in this particular setting.

Repayment of loans was a new source of stress-While participation in the intervention relieved stress and anxiety about food security, income and health more broadly, participation also presented a source of external stress for a few participants. Many spoke about increased stress from experiences with the microfinance loan. Loan repayment was a major concern among participants, who felt that repaying the loan presented a significant economic burden:

We were given loans for the farm inputs, and at times you can get a call asking for repayment when you are really financially incapacitated and that stressed me (mano nomiya parruok, literally 'gave me anxieties') because I had to think about where and how I would get the money to repay the loans. That has been my source of 
stress since joining Shamba Maisha. (Male participant, intervention end, 41 years old)

The unseasonably heavy rainfall and challenges with the first of two harvests during the time of the study exacerbated the stress from loan repayment. Other participants reported how "stressful it is that [they] are required to repay the loan for crops that did not grow." Many participants expressed concern that weather patterns dictated their ability to repay the loan in a timely manner:

It stressed me when I cultivated the seeds that I was given which got destroyed by the hailstorm. I got worried that I was required to repay the loan but I did not have a way to repay it as my crops had been destroyed by the hailstorm. (Female participant, early intervention, 31 years old)

\section{Discussion}

Despite recognition that food security is linked to mental health, few structural livelihoods interventions exist to reduce depressive and anxious symptomology. We conducted longitudinal, qualitative research in southwestern Kenya alongside a pilot trial of an agricultural and finance intervention with HIV-positive farmers. Through our qualitative data, we found that participants perceived that their HIV-related health and mental health improved. Participants described several mechanisms through which mental health improvements took place, including: improved food insecurity and income, increased productivity, staying busy, creating fruitful routines around farm work, and shifts in identity that led them to feel as if they were active and engaged members of the community.

Our qualitative findings that increased household food security was an important mechanism towards improved mental health align with previous work from other SSA settings that demonstrated how the precarious and uncertain nature of food security can be directly tied to anxiety and depression (Hadley \& Patil, 2008; Hadley et al., 2008; Tsai et al., 2012a). Similarly, food insecurity has been shown to be an important contributor towards chronic stress elsewhere (Hadley \& Patil, 2008; Maluccio et al., 2016). Our findings extend this work by showing how a livelihood intervention to improve household food security may reduce multiple aspects of mental health including stress, depressive symptoms and anxiety, and improve mood and hopefulness for the future. This qualitative study provides the foundation for future hypothesis-testing research by identifying the key pathways linking livelihood interventions on food insecurity towards improved mental health.

Other important mechanisms were that the livelihood intervention improved mental health when participants stayed engaged and productive through farming work, and also because the intervention helped to both restore a sense of purpose and improve their interconnectedness to others. Previous research has shown that lack of purpose in society is a driver of poor mental health among HIV-infected individuals (Litwinczuk \& Groh, 2007; Lyon \& Younger, 2001). This finding is supported by other research that has shown that economic interventions help participants regain morale and vision for the future (ChristyMcMullin et al., 2009; Holmes, Winskell, Hennink, \& Chidiac, 2011; Karlan \& Zinman, 2010). A crucial extension of this previous economic research is the way that this livelihoods 
intervention linked participants back to a social position of being productive, active, and healthy. In addition, in many sub-Saharan African settings, the construct of mental health is deeply embedded in the social connections of a community (Kpanake, 2018), so influencing mental health necessarily requires altering an individual's interconnectedness to others.

Two other mechanisms from previous qualitative studies on the Shamba Maisha intervention are worth noting, though they are not explored in-depth here. Qualitative findings suggest that the intervention had a positive influence on gender-related power dynamics and enhanced relationship quality (Zakaras et al., 2016), all factors that may, in turn, alter mental health of participants. Certainly, other economic interventions have seen reductions in partner conflict and domestic violence alongside decreases in psychological distress (Haushofer \& Shapiro, 2016). Also, the intervention showed qualitative evidence of decreased HIV-related stigma (Tsai et al., 2017), which has similar close ties to mental health.

As Shamba Maisha may have improved mental health through a number of mechanisms, above and beyond improved food security, this may explain why our results diverge from previous null findings in food supplementation studies (Maluccio et al., 2016; Oketch et al., 2011; Rawat et al., 2014). Targeted food supplementation, while providing critical nutritional support, does not fully ameliorate food insecurity if individuals have ongoing anxiety about their food supply, or feel that it is socially unacceptable to rely on clinic-based or other programs to feed themselves or their families (Byron, Gillespie, \& Nangami, 2008; Weiser et al., 2011). Similarly, direct food supplementation does little to help participants find a sense of purpose or develop skills for self-reliance, both of which may be crucial elements to attaining good mental health. For those who are stigmatised and marginalized, as those with food insecurity and HIV often are, livelihood interventions can contribute powerfully to social reintegration and reversal of status loss (Tsai, Bangsberg, \& Weiser, 2013)—which may be even more important than short-term gains in food security.

Finally, through the process of carrying out this study, we also identified two local constructs of mental health, an important contribution for mental health research that aims to work transculturally (Kako, Wendorf, Stevens, Ngui, \& Otto-Salaj, 2016; Mutumba et al., 2015). First, participants described that the intervention gave them a feeling of "alertness," and helped the "mind be very packed." Several participants described that in this more positive state of mental health, they found they had little space for destructive or depressive thoughts. A more robust understanding of how participants use a "busy mind" as a coping strategy should be a focus of future work. Participants also described that when the mind is "settled" or "clear," they are able to make good decisions and that "the mind is at peace." This interpretation of mental health aligns with findings from other SSA settings suggesting that HIV-positive patients consider poor mental health to be a state of "thinking too much" (Davies, Schneider, Nyatsanza, \& Lund, 2016; Haroz et al., 2016; Kidia et al., 2015). In other studies, financial hardship has been noted as a driver of repetitive, ruminating thought patterns (Kidia et al., 2015; Lund et al., 2011), which is a well-documented symptom of both anxiety and depression (Just \& Alloy, 1997; Nolen-Hoeksema, 2000). Participant rumination was decreased, suggesting that one mechanism through which livelihood interventions may 
influence mental health is by altering poverty, which serves as an underlying driver of repetitive, worrying thoughts in this population.

\section{Implications for research, intervention, and policy}

Shamba Maisha adds to what is known in SSA about structural means to improve mental health interventions. Future research should further explore the mechanisms through which livelihoods can improve mental health in order to refine theory and research in ways that make intervention effects more measurable. In addition to locally developed psychological interventions to target mental health and depression in SSA (Futterman et al., 2010; Kaaya et al., 2013), this research suggests that livelihoods may be an important avenue to improve mental health. To date, few interventions exist to improve HIV-related mental health in SSA settings (Collins, Holman, Freeman, \& Patel, 2006; Sherr, Clucas, Harding, Sibley, \& Catalan, 2011). A systematic review of cognitive behavioral interventions for common mental disorders within HIV-positive populations found no extant literature from SSA (Spies, Asmal, \& Seedat, 2013). Since that time, group interpersonal therapy interventions have demonstrated mixed success in improving mental health in SSA settings. Interventions in Uganda and South Africa demonstrated significant decreases in depression among HIVpositive patients (Nakimuli-Mpungu et al., 2015; Petersen, Hanass Hancock, Bhana, \& Govender, 2014). Yet, two other studies of group-based therapy showed no significant changes in depression among HIV-infected women (Kaaya et al., 2013; Mundell et al., 2011).

These pilot studies also highlight practical and theoretical challenges that may hinder wider scale-up. Evidence-based interventions are often designed to be delivered by skilled mental health practitioners (Mundell et al., 2011; Nakimuli-Mpungu et al., 2015). In SSA, where a single mental health professional serves roughly 70,000 people (WHO, 2015), such models may face feasibility constraints. Communities themselves may be unwilling to support 'talking' treatments if these approaches are unfamiliar or misaligned with social norms in the setting (Patel, Chowdhary, Rahman, \& Verdeli, 2011). Retention within interventions that require multiple sessions is a challenge in settings where patients must weigh the value of clinic visits against other activities, such as income generation (Mundell et al., 2011; Patel et al., 2011; Petersen et al., 2014). Thus, the very therapies that are deemed efficacious for HIV-positive populations in resource-rich settings (Safren et al., 2009) may be infeasible to deliver in SSA settings. It is possible that group-based interventions could have a better acceptability than traditional individual mental health therapies. The group-based nature of livelihood interventions among HIV-positive patients bring benefits associated with pooling resources, providing peer social support, and instrumental support around health (Roopnaraine, Rawat, Babirye, Ochai, \& Kadiyala, 2012).

There are important considerations for financial interventions and their potential to increase stress among participants. We learned from a few intervention participants that loan repayment was a source of increased stress. Others have noted that microfinance may be a stress-inducing intervention, since it asks clients to repay loans on a rigid timetable (Fernald et al., 2008). Multiple studies have shown null effects for financial interventions on mental health (Ahmed, 2005; Christy-McMullin et al., 2009; Han et al., 2009; Karlan \& Zinman, 
2010; Kayser et al., 2010; Masud Ahmed \& Chowdhury Abbas, 2001), perhaps in part because stress-relieving aspects of increased cash flow are outweighed by the anxiety of repaying a loan. That Shamba Maisha included a microfinance program that did not require collateral for those unable to repay the loan may be a key differentiator for its impact on mental health. Moreover, Shamba Maisha as an intervention offered more than traditional microfinance models that have been linked to mental health declines (Ashta et al., 2015; Fernald et al., 2008). It is probable that accessing land, participating in agricultural training, growing crops, and receiving a loan to produce income was better for mental health than simply income alone.

\section{Limitations}

There were several important limitations to our study. Qualitative data can help interpret mechanisms but these data are inappropriate for determining the impact of the intervention on mental health outcomes. We did conduct this qualitative data alongside a pilot randomized control trial, but the pilot trial was not adequately powered to examine differences in mental health between the intervention and control arms. In the future, longitudinal, qualitative research should be paired with a larger randomized control trial to determine whether mental health shifts were a measurable result of the intervention. It is possible that the qualitative interview format inflated the perceived impact of the program, for example if questions were presented in a leading way. We aimed to mitigate this limitation by training researchers to ask open-ended questions and by using longitudinal data to confirm shifts in participant responses over time. Social desirability bias may have influenced the data if participants perceived that the qualitative researchers were a part of the intervention team or if participants believed that providing favorable responses would create opportunities to gain material benefit. To minimize this bias, we hired local researchers who were not involved in intervention delivery or any other aspect of the study, and assured them that their responses would not be shared with other members of the study team..

Nevertheless, it can be challenging for participants to distinguish between intervention staff and external research teams, so the potential bias for conducting qualitative interviews within an intervention cannot be completely eliminated.

\section{Conclusion}

Despite a growing consensus that food insecurity leads to worsened mental health among PLHIV, the existing literature provides little knowledge about how best to remedy this vicious cycle in practice. Our data support that livelihood interventions may provide an important strategy for improving mental health in SSA settings by addressing the structural drivers of mental health, including poverty and food security, and by improving self-efficacy, work productivity, social connectedness and hope. humble

\section{Biography}

Abigail M. Hatcher, PhD, MPhil is an Assistant Professor at the University of the Witwatersrand and an Honorary Researcher at the University of California, San Francisco. Dr Hatcher ${ }^{1}$ s research examines the influence of mental health, poverty, and intimate partner violence on HIV care and treatment. She is leads a trial testing community mobilization for 
reducing men ${ }^{1} \mathrm{~s}$ use of partner violence in Johannesburg and contributes to a home-based couples counseling trial for improving perinatal health outcomes in rural Kenya.

Lee Lemus Hufstedler is a medical student in the UC Berkeley-UCSF Joint Medical Program, currently conducting master's research on the health needs of homeless transgender youth. Before beginning medical school, Lee worked for almost a decade as a social justice community organizer around sexual and reproductive health and rights and coordinated community-based research on structural drivers of HIV-related health outcomes.

Kathryne Doria, RN, MS, is an advanced practice registered nursing student at Yale University. Her research and clinical interests focus on improving primary care services to minority and rural populations, with a specific focus on the linkages between chronic disease, food insecurity, and structural factors shaping disease outcomes.

Shari L. Dworkin, PhD, MS is Professor and Dean at the University of Washington Bothell School of Nursing and Health Studies. Her research is focused on gender relations and HIV prevention, treatment and care. Dr Dworkin is currently Co-PI on a gender-transformative intervention designed to improve men's acceptance of family planning in Western Kenya.

Elly Weke is a Study Manager at the Kenya Medical Research Institute (KEMRI). He conducts clinical and implementation research in HIV/AIDS and reproductive health, including the integration of livelihood and multisectoral interventions to improve household economic and health outcomes.

Amy A. Conroy, PhD MPH is a behavioral scientist and Assistant Professor at the Center for AIDS Prevention Studies at the University of California San Francisco. Dr. Conroy's research seeks to understand and intervene upon the association between couple relationship dynamics and health behaviors related to infectious and chronic disease in sub-Saharan Africa. Dr. Conroy is currently leading the Umodzi M'Banja Project ("Unity is the family") to develop a couple-based intervention to optimize HIV care and treatment engagement in rural Malawi.

Craig R. Cohen, MD, MPH is a Professor in the Department of Obstetrics, Gynecology \& Reproductive Sciences at the University of California San Francisco (UCSF), and CoDirector of University of California Global Health Institute (UCGHI). He conducts research in three areas including: 1) HIV/AIDS care, support and prevention in low-income countries, 2) livelihood interventions, and 3) their intersection with sexual \& reproductive health. He is the principal investigator of the PEPFAR/CDC-funded Family AIDS Care \& Education Services (FACES) an HIV care, treatment and prevention program in Kenya, and multiple NIH research and training programs.

Elizabeth Bukusi, MBChB, MMed, PhD, MPH, PGD, MBE, is a Chief Research Officer at the Kenya Medical Research Institute (KEMRI), a Research Professor at the university of Washington and volunteer faculty at the University of California San Francisco. She is a visiting Scientist at the University of Nairobi, an honorary lecturer at Aga Khan University in Nairobi and is faculty at the Centre for Biomedical Ethics and Culture at the Sind Institute in Karachi. Her primary research interest includes STIs, reproductive health and HIV 
prevention, care and treatment in addition to interest in ethics and the development of systems and structures for regulating research. She has had a focus on capacity building for many years and has been engaged in the training and mentorship young scientists. She serves on many international boards, taskforces, and committees.

Dr. Sheri Weiser, MD, MPH, MA, is an internist, and Associate Professor of Medicine at the Division of HIV, Infectious Disease and Global Medicine at UCSF. Her research focuses on the impact of structural barriers to HIV prevention, treatment, and care in underserved populations in resource poor and resource rich settings. She is particularly interested in the role of food insecurity as a barrier to sustained engagement in care, adherence and optimal health among both HIV-infected and uninfected individuals, and in devising and evaluating food security and livelihood interventions as a way to improve health outcomes.

\section{References}

Ahmed SM (2005). Intimate partner violence against women: Experiences from a woman-focused development programme in Matlab, Bangladesh. Journal of Health Population and Nutrition, 23(1), 95-101.

Antelman G, Kaaya S, Wei R, Mbwambo J, Msamanga GI, Fawzi WW, \& Fawzi MC (2007). Depressive symptoms increase risk of HIV disease progression and mortality among women in Tanzania. J Acquir Immune Defic Syndr, 44(4), 470-477. [PubMed: 17179766]

Ashta A, Khan S, \& Otto P (2015). Does microfinance cause or reduce suicides? Policy recommendations for reducing borrower stress. Strategic Change, 24(2), 165-190.

Becchetti L, \& Conzo P (2010). Credit access and life satisfaction: evaluating the non monetary effects of micro finance. AICCON Working Papers.

Bernard H (2006). Research Methods in Anthropology: Qualitative and Quantitative Approaches (4th ed.). Lanham, MD: AltaMira Press.

Burgess RA (2015). Supporting mental health in South African HIV-affected communities: primary health care professionals' understandings and responses. Health Policy Plan, 30(7), 917-927. [PubMed: 25161270]

Byron E, Gillespie S, \& Nangami M (2008). Integrating nutrition security with treatment of people living with HIV: lessons from Kenya. Food Nutr Bull, 29(2), 87-97. [PubMed: 18693472]

Charmaz K (2008). Constructionism and the grounded theory method. Handbook of constructionist research, 397-412.

Chibanda D, Benjamin L, Weiss HA, \& Abas M (2014). Mental, neurological, and substance use disorders in people living with HIV/AIDS in low- and middle-income countries. J Acquir Immune Defic Syndr, 67 Suppl 1, S54-67. [PubMed: 25117961]

Christy-McMullin K, Shobe MA, \& Wills J (2009). Arkansas IDA programs: Examining asset retention and perceptions of well-being. Journal of Social Service Research, 35(1), 65-76.

Cohen CR, Steinfeld RL, Weke E, Bukusi EA, Hatcher AM, Shiboski S, ... Otieno P (2015). Shamba Maisha: Pilot agricultural intervention for food security and HIV health outcomes in Kenya: design, methods, baseline results and process evaluation of a cluster-randomized controlled trial. SpringerPlus, 4(1), 122. [PubMed: 25992307]

Collins PY, Holman AR, Freeman MC, \& Patel V (2006). What is the relevance of mental health to HIV/AIDS care and treatment programs in developing countries? A systematic review. AIDS, 20(12), 1571-1582. [PubMed: 16868437]

Davies T, Schneider M, Nyatsanza M, \& Lund C (2016). "The sun has set even though it is morning”: Experiences and explanations of perinatal depression in an urban township, Cape Town. Transcult Psychiatry, 53(3), 286-312. [PubMed: 26905932]

Evans DL, Ten Have TR, Douglas SD, Gettes DR, Morrison M, Chiappini MS, ... Petitto JM (2002). Association of depression with viral load, CD8 T lymphocytes, and natural killer cells in women with HIV infection. Am J Psychiatry, 159(10), 1752-1759. [PubMed: 12359683] 
Fernald LCH, Hamad R, Karlan D, Ozer EJ, \& Zinman J (2008). Small individual loans and mental health: a randomized controlled trial among South African adults. BMC Public Health, 8, 14. [PubMed: 18194536]

Field E, Pande R, Papp J, \& Park YJ (2012). Repayment flexibility can reduce financial stress: a randomized control trial with microfinance clients in India. PLoS One, 7(9), e45679. [PubMed: 23049836]

Flisher AJ, Lund C, Funk M, Banda M, Bhana A, Doku V, ... Green A (2007). Mental health policy development and implementation in four African countries. J Health Psychol, 12(3), 505-516. [PubMed: 17440000]

Glass N, Perrin NA, Kohli A, \& Remy MM (2014). Livestock/animal assets buffer the impact of conflict-related traumatic events on mental health symptoms for rural women. PLoS One, 9(11), e111708. [PubMed: 25419743]

Hadley C, \& Patil CL (2006). Food insecurity in rural Tanzania is associated with maternal anxiety and depression. Am J Hum Biol, 18(3), 359-368. [PubMed: 16634017]

Hadley C, \& Patil CL (2008). Seasonal changes in household food insecurity and symptoms of anxiety and depression. Am J Phys Anthropol, 135(2), 225-232. [PubMed: 18046777]

Hadley C, Tegegn A, Tessema F, Cowan JA, Asefa M, \& Galea S (2008). Food insecurity, stressful life events and symptoms of anxiety and depression in east Africa: evidence from the Gilgel Gibe growth and development study. J Epidemiol Community Health, 62(11), 980-986. [PubMed: 18854502]

Han C-K, Grinstein-Weiss M, \& Sherraden M (2009). Assets beyond Savings in Individual Development Accounts. Social Service Review, 83(2), 221-244.

Haroz E, Ritchey M, Bass J, Kohrt B, Augustinavicius J, Michalopoulous L, ... Bolton P (2016). How is depression experienced around the world? A systematic review of qualitative literature. Social Science \& Medicine.

Hatala AR (2012). The status of the "biopsychosocial" model in health psychology: Towards an integrated approach and a critique of cultural conceptions. Open Journal of Medical Psychology, 1(04), 51.

Haushofer J, \& Shapiro J (2016). The short-term impact of unconditional cash transfers to the poor: Experimental evidence from Kenya. The Quarterly Journal of Economics, 131(4), 1973-2042.

Holmes K, Winskell K, Hennink M, \& Chidiac S (2011). Microfinance and HIV mitigation among people living with HIV in the era of anti-retroviral therapy: emerging lessons from Cote d'Ivoire. Glob Public Health, 6(4), 447-461. [PubMed: 20936558]

Jain S, \& Orr D (2016). Ethnographic perspectives on global mental health. Transcultural Psychiatry, 53(6), 685-695. [PubMed: 28317467]

Just N, \& Alloy LB (1997). The response styles theory of depression: tests and an extension of the theory. Journal of abnormal psychology, 106(2), 221. [PubMed: 9131842]

Kaaya SF, Blander J, Antelman G, Cyprian F, Emmons KM, Matsumoto K, ... Smith Fawzi MC (2013). Randomized controlled trial evaluating the effect of an interactive group counseling intervention for HIV-positive women on prenatal depression and disclosure of HIV status. AIDS Care, 25(7), 854-862. [PubMed: 23383726]

Kako PM, Wendorf AR, Stevens PE, Ngui E, \& Otto-Salaj LL (2016). Contending with Psychological Distress in Contexts with Limited Mental Health Resources: HIV-Positive Kenyan Women's Experiences. Issues in mental health nursing, 37(1), 2-9. [PubMed: 26818927]

Karlan D, \& Zinman J (2010). Expanding credit access: Using randomized supply decisions to estimate the impacts. Review of Financial Studies, 23(1), 433.

Kayser K, Lombe M, Newransky C, Tower G, \& Raj PM (2010). Microcredit Self-Help Groups for Widowed and Abandoned Women in South India: Do They Help? Journal of Social Service Research, 36(1), 12-23.

Kenya National Bureau of Statistics. (2008). Food Insecurity Assessment in Kenya. Retrieved from Nairobi:

Kenya National Bureau of Statistics and ICF Macro. (2010). Kenya Demographic and Health Survey 2008-09. Retrieved from Calverton, Maryland: 
Kidia K, Machando D, Bere T, Macpherson K, Nyamayaro P, Potter L, ... Abas M (2015). 'I was thinking too much': experiences of HIV-positive adults with common mental disorders and poor adherence to antiretroviral therapy in Zimbabwe. Trop Med Int Health, 20(7), 903-913. [PubMed: 25754063]

Kilburn K, Thirumurthy H, Halpern CT, Pettifor A, \& Handa S (2016). Effects of a Large-Scale Unconditional Cash Transfer Program on Mental Health Outcomes of Young People in Kenya. J Adolesc Health, 58(2), 223-229. [PubMed: 26576822]

Kpanake L (2018). Cultural concepts of the person and mental health in Africa. Transcultural psychiatry, 55(2), 198-218. [PubMed: 29400136]

Litwinczuk KM, \& Groh CJ (2007). The relationship between spirituality, purpose in life, and wellbeing in HIV-positive persons. Journal of the Association of Nurses in AIDS Care, 18(3), 13-22.

Lund C, Breen A, Flisher AJ, Kakuma R, Corrigall J, Joska JA, ... Patel V (2010). Poverty and common mental disorders in low and middle income countries: A systematic review. Soc Sci Med, 71(3), 517-528. [PubMed: 20621748]

Lund C, De Silva M, Plagerson S, Cooper S, Chisholm D, Das J, ... Patel V (2011). Poverty and mental disorders: breaking the cycle in low-income and middle-income countries. Lancet, 378(9801), 1502-1514. [PubMed: 22008425]

Lyon DE, \& Younger JB (2001). Purpose in life and depressive symptoms in persons living with HIV disease. Journal of Nursing Scholarship, 33(2), 129-133. [PubMed: 11419307]

Macours K, Schady N, \& Vakis R (2012). Cash transfers, behavioral changes, and cognitive development in early childhood: evidence from a randomized experiment. American Economic Journal: Applied Economics, 4(2), 247-273.

Maluccio JA, Wu F, Rokon RB, Rawat R, \& Kadiyala S (2016). Assessing the Impact of Food Assistance on Stigma Among People Living with HIV in Uganda Using the HIV/AIDS Stigma Instrument-PLWA (HASI-P). AIDS Behav.

Masud Ahmed S, \& Chowdhury Abbas M (2001). Micro-credit and emotional well-being: experience of poor rural women from Matlab, Bangladesh. World Development, 29(11), 1957-1966.

Mohindra KS, Haddad S, \& Narayana D (2008). Can microcredit help improve the health of poor women? Some findings from a cross-sectional study in Kerala, India. International Journal for Equity in Health, 7, 14. [PubMed: 18533020]

Mundell JP, Visser MJ, Makin JD, Kershaw TS, Forsyth BW, Jeffery B, \& Sikkema KJ (2011). The impact of structured support groups for pregnant South African women recently diagnosed HIV positive. Women Health, 51(6), 546-565. [PubMed: 21973110]

Mutumba M, Resnicow K, Bauermeister JA, Harper GW, Musiime V, Snow RC, \& Lepkowski JM (2015). Development of a psychosocial distress measure for Ugandan adolescents living with HIV. AIDS Behav, 19(2), 380-392. [PubMed: 25577026]

Nakimuli-Mpungu E, Bass JK, Alexandre P, Mills EJ, Musisi S, Ram M, ... Nachega JB (2012). Depression, alcohol use and adherence to antiretroviral therapy in sub-Saharan Africa: a systematic review. AIDS Behav, 16(8), 2101-2118. [PubMed: 22116638]

Nakimuli-Mpungu E, Wamala K, Okello J, Alderman S, Odokonyero R, Mojtabai R, ... Musisi S (2015). Group support psychotherapy for depression treatment in people with HIV/AIDS in northern Uganda: a single-centre randomised controlled trial. Lancet HIV, 2(5), e190-199. [PubMed: 26423001]

Nakimuli-Mpungu E, Wamala K, Okello J, Alderman S, Odokonyero R, Musisi S, \& Mojtabai R (2014). Developing a culturally sensitive group support intervention for depression among HIV infected and non-infected Ugandan adults: a qualitative study. J Affect Disord, 163, 10-17. [PubMed: 24836082]

Ngui EM, Khasakhala L, Ndetei D, \& Roberts LW (2010). Mental disorders, health inequalities and ethics: A global perspective. Int Rev Psychiatry, 22(3), 235-244. [PubMed: 20528652]

Nolen-Hoeksema S (2000). The role of rumination in depressive disorders and mixed anxiety/ depressive symptoms. Journal of abnormal psychology, 109(3), 504. [PubMed: 11016119]

Oketch JA, Paterson M, Maunder EW, \& Rollins NC (2011). Too little, too late: comparison of nutritional status and quality of life of nutrition care and support recipient and non-recipients 
among HIV-positive adults in KwaZulu-Natal, South Africa. Health Policy, 99(3), 267-276. [PubMed: 20884072]

Owusu-Addo E, Renzaho A, \& Smith BJ (2018). The impact of cash transfers on social determinants of health and health inequalities in sub-Saharan Africa: a systematic review. Health Policy and Planning.

Ozer EJ, Fernald LC, Weber A, Flynn EP, \& VanderWeele TJ (2011). Does alleviating poverty affect mothers' depressive symptoms? A quasi-experimental investigation of Mexico's Oportunidades programme. Int J Epidemiol, 40(6), 1565-1576. [PubMed: 21737404]

Palermo T, Rawat R, Weiser SD, \& Kadiyala S (2013). Food access and diet quality are associated with quality of life outcomes among HIV-infected individuals in Uganda. PLoS One, 8(4), e62353. [PubMed: 23638049]

Patel V, Chowdhary N, Rahman A, \& Verdeli H (2011). Improving access to psychological treatments: lessons from developing countries. Behav Res Ther, 49(9), 523-528. [PubMed: 21788012]

Patel V, \& Kleinman A (2003). Poverty and common mental disorders in developing countries. Bull World Health Organ, 81(8), 609-615. [PubMed: 14576893]

Patton M (2002). Qualitative Research and Evaluation Methods (3rd ed.). Thousand Oaks, CA: Sage Publications.

Petersen I, Hanass Hancock J, Bhana A, \& Govender K (2014). A group-based counselling intervention for depression comorbid with HIV/AIDS using a task shifting approach in South Africa: a randomized controlled pilot study. J Affect Disord, 158, 78-84. [PubMed: 24655769]

Pronyk PM, Harpham T, Busza J, Phetla G, Morison LA, Hargreaves JR, ... Porter, J. D. (2008). Can social capital be intentionally generated? a randomized trial from rural South Africa. Soc Sci Med, 67(10), 1559-1570. [PubMed: 18771833]

Rawat R, Faust E, Maluccio JA, \& Kadiyala S (2014). The impact of a food assistance program on nutritional status, disease progression, and food security among people living with HIV in Uganda. J Acquir Immune Defic Syndr, 66(1), e15-22. [PubMed: 24326603]

Roopnaraine T, Rawat R, Babirye F, Ochai R, \& Kadiyala S (2012). "The group" in integrated HIV and livelihoods programming: opportunity or challenge? AIDS care, 24(5), 649-657. [PubMed: 22087549]

Safren SA, O’Cleirigh C, Tan JY, Raminani SR, Reilly LC, Otto MW, \& Mayer KH (2009). A randomized controlled trial of cognitive behavioral therapy for adherence and depression (CBTAD) in HIV-infected individuals. Health Psychol, 28(1), 1-10. [PubMed: 19210012]

Sherr L, Clucas C, Harding R, Sibley E, \& Catalan J (2011). HIV and depression--a systematic review of interventions. Psychol Health Med, 16(5), 493-527. [PubMed: 21809936]

Sikkema KJ, Dennis AC, Watt MH, Choi KW, Yemeke TT, \& Joska JA (2015). Improving mental health among people living with HIV: a review of intervention trials in low- and middle-income countries. Glob Ment Health (Camb), 2.

SocioCultural Research Consultants, L. (Producer). (2013). Dedoose Version 4.5, web application for managing, analyzing, and presenting qualitative and mixed method research data. Retrieved from (http://www.dedoose.com)

Spies G, Asmal L, \& Seedat S (2013). Cognitive-behavioural interventions for mood and anxiety disorders in HIV: a systematic review. J Affect Disord, 150(2), 171-180. [PubMed: 23688915]

Ssewamala FM, Neilands TB, Waldfogel J, \& Ismayilova L (2012). The impact of a comprehensive microfinance intervention on depression levels of AIDS-orphaned children in Uganda. J Adolesc Health, 50(4), 346-352. [PubMed: 22443837]

Steel Z, Marnane C, Iranpour C, Chey T, Jackson JW, Patel V, \& Silove D (2014). The global prevalence of common mental disorders: a systematic review and meta-analysis 1980-2013. Int J Epidemiol, 43(2), 476-493. [PubMed: 24648481]

Subbaraman R, Nolan L, Shitole T, Sawant K, Shitole S, Sood K, ... Patil-Deshmukh A (2014). The psychological toll of slum living in Mumbai, India: a mixed methods study. Soc Sci Med, 119, 155-169. [PubMed: 25189736]

Tesfaye M, Kaestel P, Olsen MF, Girma T, Yilma D, Abdissa A, ... Hanlon C (2016). Food insecurity, mental health and quality of life among people living with HIV commencing antiretroviral 
treatment in Ethiopia: a cross-sectional study. Health Qual Life Outcomes, 14, 37. [PubMed: 26940394]

Tsai AC (2014). Reliability and validity of depression assessment among persons with HIV in subSaharan Africa: systematic review and meta-analysis. J Acquir Immune Defic Syndr, 66(5), 503511. [PubMed: 24853307]

Tsai AC, Bangsberg DR, Frongillo EA, Hunt PW, Muzoora C, Martin JN, \& Weiser SD (2012a). Food insecurity, depression and the modifying role of social support among people living with HIV/ AIDS in rural Uganda. Soc Sci Med, 74(12), 2012-2019. [PubMed: 22513248]

Tsai AC, Bangsberg DR, Frongillo EA, Hunt PW, Muzoora C, Martin JN, \& Weiser SD (2012b). Food insecurity, depression and the modifying role of social support among people living with HIV/ AIDS in rural Uganda. Soc Sci Med.

Tsai AC, Bangsberg DR, \& Weiser SD (2013). Harnessing poverty alleviation to reduce the stigma of HIV in Sub-Saharan Africa. PLoS Med, 10(11), e1001557. [PubMed: 24319400]

Tsai AC, Hatcher AM, Bukusi EA, Weke E, Lemus Hufstedler L, Dworkin SL, ... Weiser SD (2017). A Livelihood Intervention to Reduce the Stigma of HIV in Rural Kenya: Longitudinal Qualitative Study. AIDS Behav, 21(1), 248-260. [PubMed: 26767535]

Tweed A, \& Charmaz K (2012). Grounded theory methods for mental health practitioners. Qualitative research methods in mental health and psychotherapy: A guide for students and practitioners, 131146.

Weiser SD, Gupta R, Tsai AC, Frongillo EA, Grede N, Kumbakumba E, ... Bangsberg DR (2012). Changes in food insecurity, nutritional status, and physical health status after antiretroviral therapy initiation in rural Uganda. J Acquir Immune Defic Syndr, 61(2), 179-186. [PubMed: 22692093]

Weiser SD, Young SL, Cohen CR, Kushel MB, Tsai AC, Tien PC, ... Bangsberg DR (2011). Conceptual framework for understanding the bidirectional links between food insecurity and HIV/ AIDS. Am J Clin Nutr, 94(6), 1729S-1739S. [PubMed: 22089434]

WHO. (2015). Mental Health Atlas 2014. Retrieved from Geneva:

Zakaras JM, Weiser SD, Hatcher AM, Weke E, Burger RL, Cohen CR, ... Dworkin SL (2016). A Qualitative Investigation of the Impact of a Livelihood Intervention on Gendered Power and Sexual Risk Behaviors Among HIV-Positive Adults in Rural Kenya. Arch Sex Behav. 


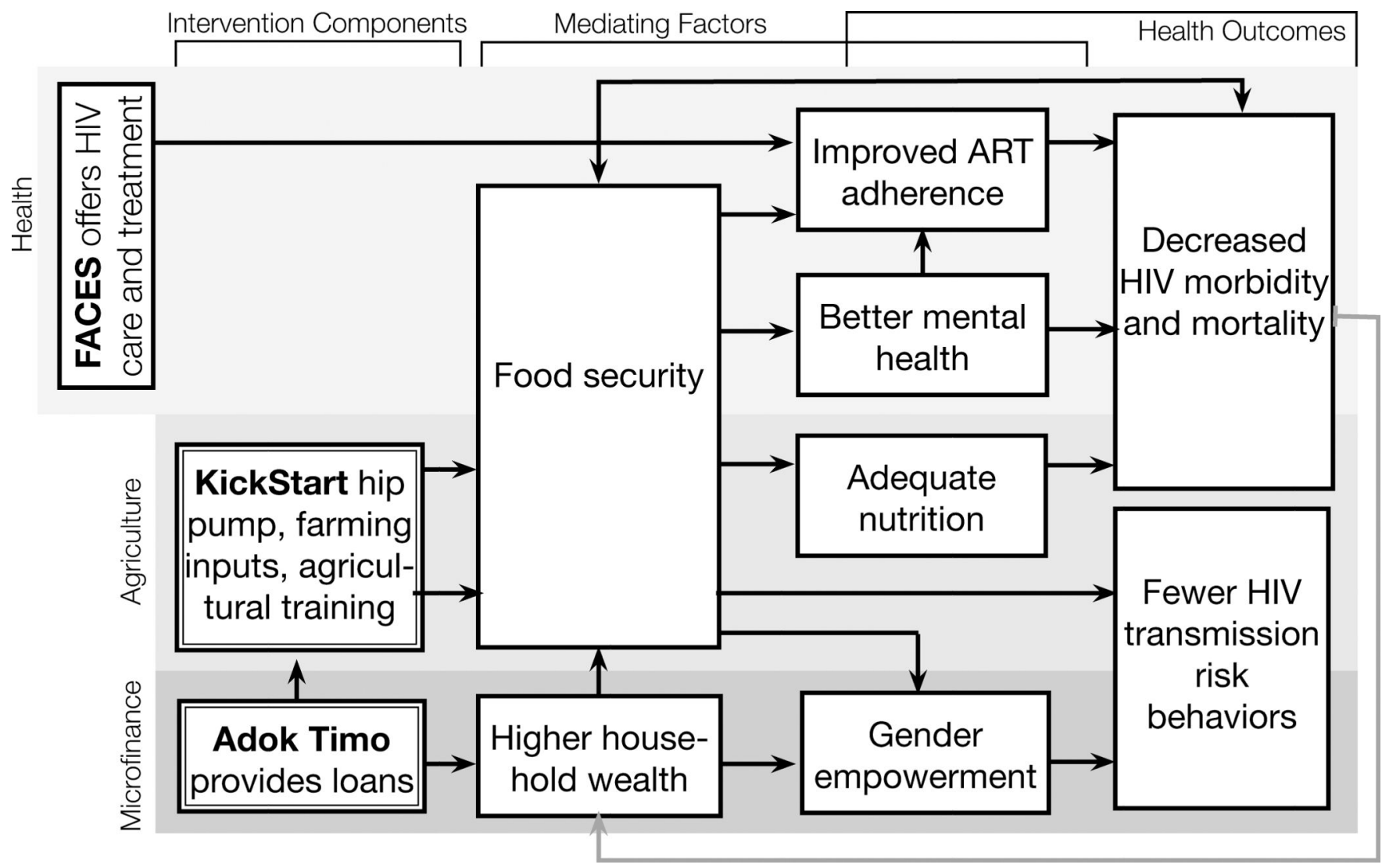

Figure 1. 


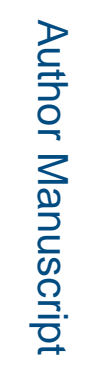

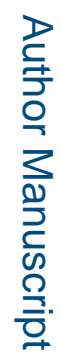

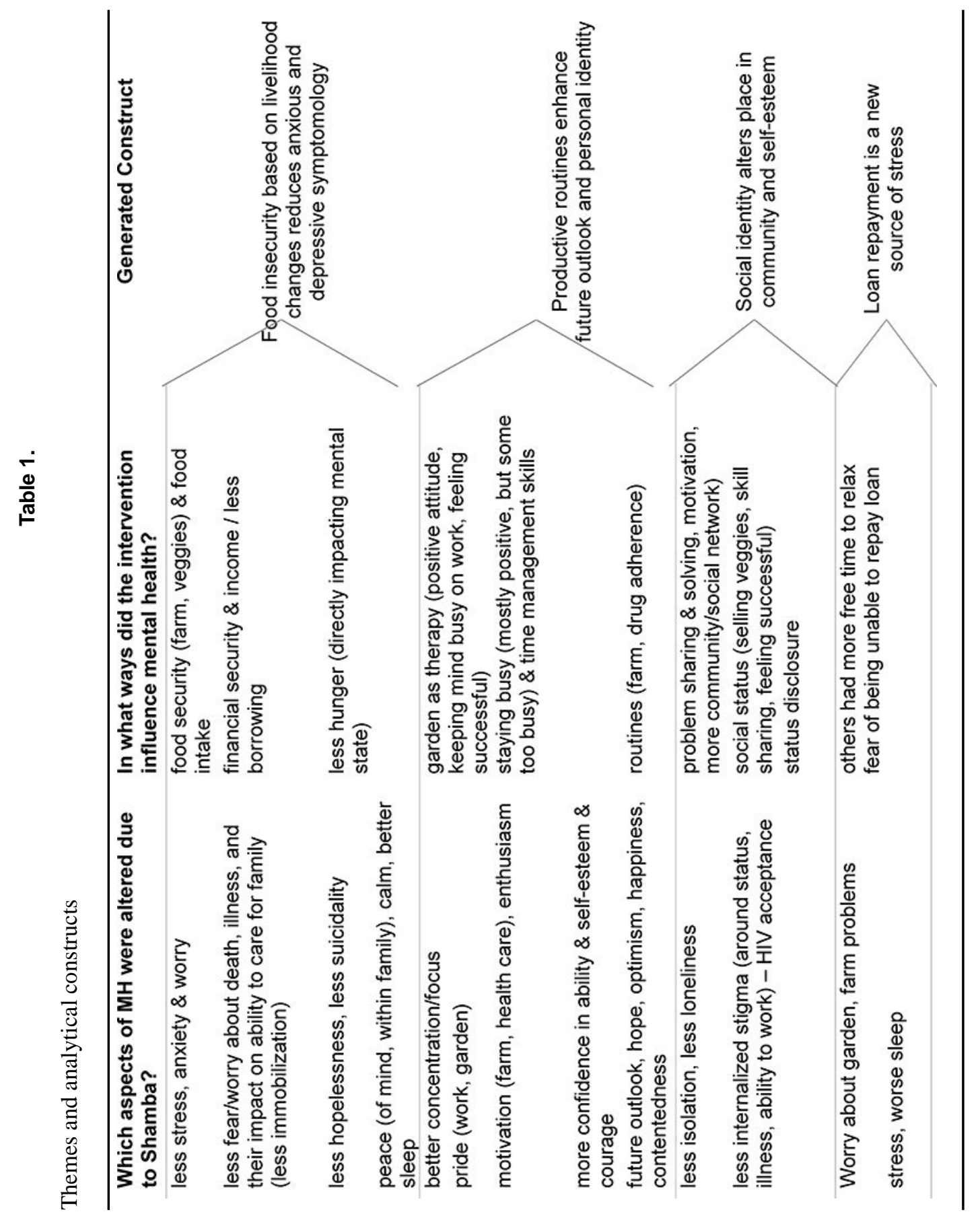

로을

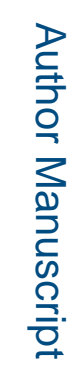

胥 
Table 2.

Characteristics of participants included in the study $(\mathrm{N}=54)$

\begin{tabular}{|c|c|c|c|}
\hline & $\begin{array}{c}\text { Intervention Arm }(\mathrm{n}=45) \\
\text { Number }(\%) \text { or Median }(\mathrm{IQR}) \\
\end{array}$ & $\begin{array}{c}\text { Control Arm }(\mathrm{n}=9) \\
\text { Number }(\%) \text { or Median (IQR) } \\
\end{array}$ & $\begin{array}{l}\text { Test statistic (t-test, chi2, Mann- } \\
\text { Whitney) p value }\end{array}$ \\
\hline \multicolumn{4}{|l|}{ Participant group } \\
\hline Followed (2 interviews) & $31(68.9)$ & - & - \\
\hline Once-off interviews & $14(31.1)$ & $9(100.0)$ & \\
\hline Gender & & & 0.354 \\
\hline Female & $26(48.1)$ & $5(55.6)$ & \\
\hline Male & $28(51.9)$ & $4(44.4)$ & \\
\hline Age, $y$ & $36(32-42)$ & $40(40-44)$ & 0.092 \\
\hline Duration of HIV treatment, $y$ & $4(2-6)$ & $4(2-4)$ & 0.333 \\
\hline \multicolumn{4}{|l|}{ Marital status } \\
\hline Married & $16(37.2)$ & $4(44.4)$ & 0.602 \\
\hline Married (polygynous) & $10(23.3)$ & $1(12.5)$ & \\
\hline Widow (single) & $13(30.2)$ & $2(22.2)$ & \\
\hline Widow (inherited) & $4(9.3)$ & $2(22.2)$ & \\
\hline Number of children & $3(3-4)$ & $3(2-3)$ & 0.117 \\
\hline Farming experience, $y$ & $12(5-20)$ & $8(7-11)$ & 0.049 \\
\hline
\end{tabular}




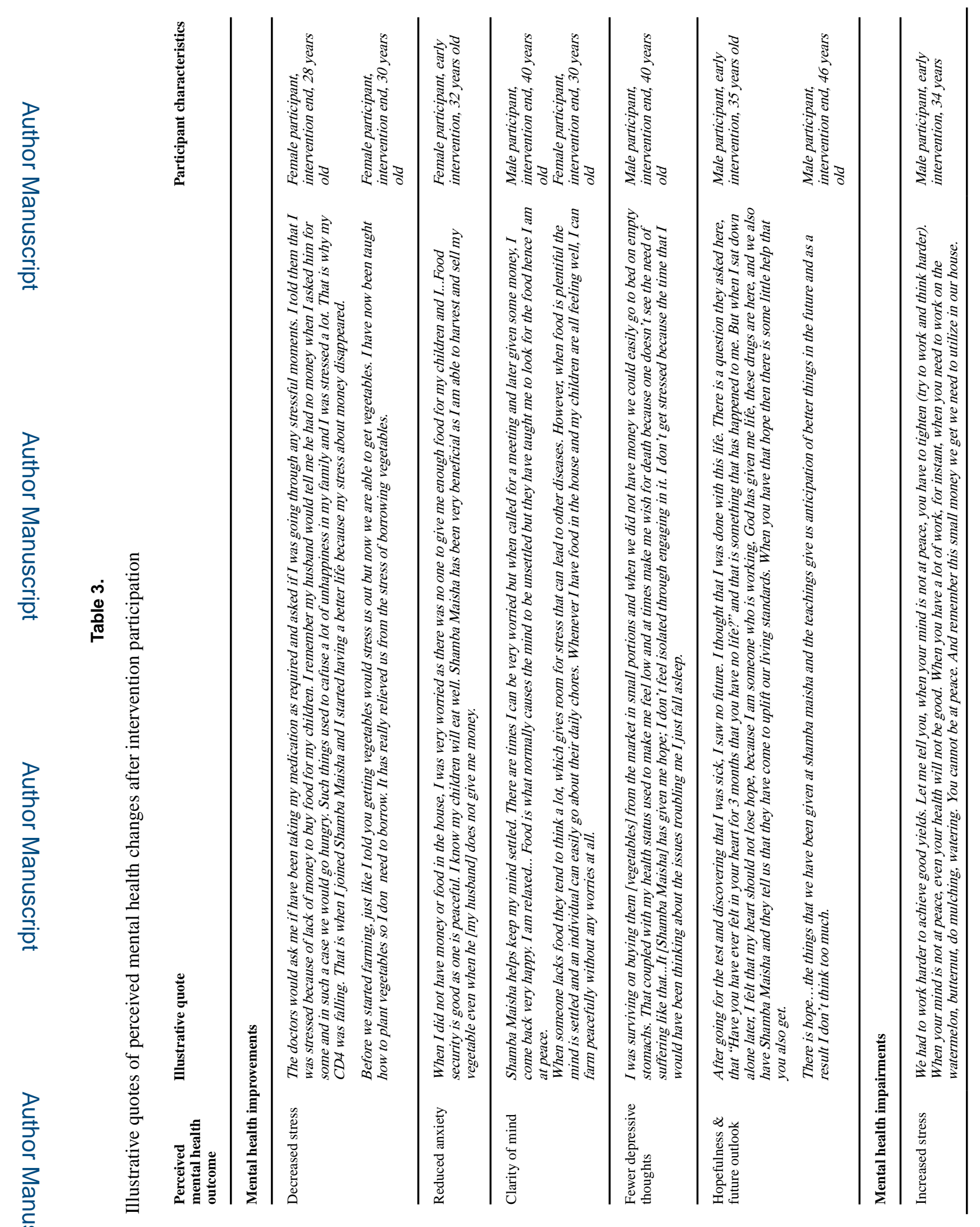

Transcult Psychiatry. Author manuscript; available in PMC 2020 May 04. 